\title{
Synthesis and Characterization of Nanocrystalline CdS and its Application to Reduction of Nitroarenes
}

\author{
P. RAJENDER REDDY ${ }^{1}$, B. PRASANNA ${ }^{2 *}$ and N. GOPIKRISHNA ${ }^{1}$ \\ ${ }^{1}$ Department of Physics, Kakatiya University, Warangal (TS), India \\ ${ }^{2}$ Department of Chemistry, Chaitanya Post graduate College (Autonomous) Kishanpura \\ Hanamkonda, Warangal (TS) 506 001, India \\ prasschem@gmail.com
}

Received 16 January 2016 / Accepted 3 February 2016

\begin{abstract}
An efficient reduction procedure for the synthesis of arylamines $\mathbf{2}(\mathbf{a}-\mathbf{h})$ from aryl nitro compounds 1(a-h) by nanocrystalline cadmium sulphide $(\mathrm{CdS})$ as catalyst under hydrochloric acid solution at $80-90{ }^{\circ} \mathrm{C}$ has been developed. The worldwide availability, larger scale synthesis, higher yields and shorter reaction times are the advantages of the present method.
\end{abstract}

Keywords: Aryl amines, CdS nanoparticles, SEM, DSC, Reduction

\section{Introduction}

Optimizing yield is important in traditional chemical synthesis but other issues need to be addressed including minimizing number of steps, simplicity, waste, atom efficiency, energy usage, safety and whether the chemistry is environmentally acceptable. Reducing the use of organic solvents can minimize the generation of waste, which is a requirement of one of the principle of green chemistry. Organic solvents are conventionally used in chemical synthesis in $\mathrm{R} \& \mathrm{D}$ and in industries processes on a large scale for heat transfer and controlling chemical reactivity. However, there are serious safety issues and costly technologically challenging demands associated with containing volatile material. Greening of chemical synthesis is formidable challenge and often requires a multi disciplinary approach. In recent years, the synthesis of nano crystalline oxide materials has been a focal point of research and developmental activities in the area of nano materials owing to the quest for their various technological applications ${ }^{1,2}$.

Chalcogenoids has attracted significant interest and still is the subject of intense investigation owing to their important non linear properties Luminescent properties, quantum size effects and other important physical and chemical properties ${ }^{3-7}$. Among these, CdS is the most interesting owing to its high photosensitivity, that makes them a promising candidate for the detection of visible radiations, enhancing efficiency of solar cells, in LEDs as sample photoconductor in optoelectronic devices ${ }^{8}$ and a number of biological applications ${ }^{9}$. 
Aryl amines are synthetically important compounds which act as precursors to the synthesis of many interesting molecules, and can be readily synthesized from aryl nitro compounds via countless reduction methods. The most general methods involve activated metal catalysis ${ }^{10}$ and transition metal catalyzed hydrogenation ${ }^{11}$, although the latter often employs harsh reaction conditions affecting other reduction sensitive functionalities such as halides, ketones, aldehydes, esters and nitriles in addition to the nitro substituent. The selective reduction of aryl nitro compounds using iron powder and dilute acid ${ }^{12}$ or stannous chloride ${ }^{13}$ have been reported as efficient methods for the synthesis of aryl amines in good yields. However notable disadvantages to these methods include high reaction temperatures, relatively long reaction times.

Following, our interest to developed simple, eco-efficient and environmentally friendly procedure for the synthesis of aromatic amines from nitro arenes by nanocrystalline $\mathrm{CdS}$ in the presence of hydrochloric acid solution. In this note also we demonstrated the synthesis and characterization of CdS nanoparticles.

\section{Experimental}

All chemicals used in our experiments were reagent grade and used without further purification. The morphology and structure of the CdS nanoparticles and products were determined by the $\mathrm{x}$ ray diffraction (XRD), FT-IR, UV-Visible spectrophotometer, SEM and DSC.

\section{Synthesis of CdS nanoparticles}

In a typical solid state reaction, $5.14 \mathrm{~g}$ of $\mathrm{CdCl}_{2} \cdot \mathrm{H}_{2} \mathrm{O}$ and $2 \mathrm{~g}$ of $\mathrm{Na}_{2} \mathrm{~S}$ were taken and ground for $10 \mathrm{~min}$ each in a clean agate pestle-mortar then, these were mixed together in a cleaned agate mortar and ground for $30 \mathrm{~min}$ to get homogeneity. The orange products were washed several times with de-ionized water and with ethanol to remove waste materials then filtered. Finally, the products were calcinated at $60{ }^{\circ} \mathrm{C}, 100{ }^{\circ} \mathrm{C}, 140{ }^{\circ} \mathrm{C}$ and $180{ }^{\circ} \mathrm{C}$ for $6 \mathrm{~h}$ named as CdS- $1, \mathrm{CdS}-2$, CdS-3 and CdS-4 respectively. Finally, the products were collected and dried under vacum.

\section{Synthesis of aromatic amines from nitroarenes $\mathbf{2}(\boldsymbol{a}-\boldsymbol{h})$}

To a solution of CdS nanoparticles $(0.15 \mathrm{mmol})$ in $20 \% \mathrm{HCl}(2 \mathrm{~mL})$ a solution of nitro arenes $\mathbf{1}(\mathbf{a}-\mathbf{h})(0.1 \mathrm{mmol})$ was added slowly at room temperature (Scheme 1$)$. The reaction mixture was refluxed at $80-90{ }^{\circ} \mathrm{C}$ for appropriate times (the reaction was monitored by TLC). After completion of reaction, the mixture was cooled to room temperature, neutralized with dil. $\mathrm{NaOH}$, then extracted with $\mathrm{CHCl}_{3}$ as solvent and dried over anhydrous $\mathrm{Na}_{2} \mathrm{SO}_{4}$. The $\mathrm{CHCl}_{3}$ was removed under vacuum to yield corresponding aromatic amines $\mathbf{2}(\mathbf{a}-\mathbf{h})$ with good yields.

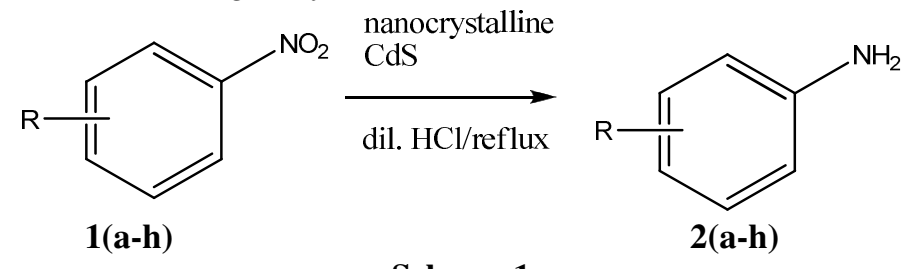

\section{Results and Discussion}

Scheme 1

Detailed studies on the reaction of aromatic nitro compounds $\mathbf{1}(\mathbf{a}-\mathbf{h})$ with CdS nanoparticles to form substituted aromatic amines $\mathbf{2}(\mathbf{a}-\mathbf{h})$ have shown that this reduction reactions are 
influenced to a considerable extent by the reagent as shown in Table 1. A comparison of the catalytic effect of nano CdS particles with various sizes were reported in Table 2 . As can be seen in the table, nanocrystalline $\mathrm{CdS}$ particles $(\mathrm{CdS}-4)$ with size $2.5 \mathrm{~nm}$ displays a substantial activity in the reduction reaction than the other CdS nanoparticles (CdS-1, CdS-2 and CdS-3) under the same condition. Therefore, in this regard, the nanocrystalline CdS-4 should be having more reactive sites than other $\mathrm{CdS}$ nanoparticles and consequently higher agent activity. In addition to the above mentioned and with attention to the special structure of nano crystalline CdS, it seems that the organic species should be able to diffuse faster on the surface of this solid agent rather than the other sized CdS nanoparticles.

Table 1. Analytical data of synthesized aromatic amines 2(a-h)

Compd.

Table 2. Survey of nanocatalyst effect in the reaction for $\mathbf{2 b}$

\begin{tabular}{cccc}
\hline Entry & Reagent & Time, & Yield, \% \\
\hline 1 & CdS-1 & 2.5 & 56 \\
2 & CdS-2 & 2.2 & 65 \\
3 & CdS-3 & 1.8 & 72 \\
4 & CdS-4 & 1.5 & 78 \\
\hline
\end{tabular}




\section{Characterization of $\mathrm{CdS}$ nanoparticles}

\section{$X$-Ray diffraction}

The powder $\mathrm{x}$-ray diffraction patterns for CdS nanoparticles were recorded on a Bruker x-ray diffractometer with $\mathrm{CuK} \alpha$ radiation $\left(\lambda=1.5414^{\circ} \mathrm{A}\right)$ with $2 \theta$ ranging from $10^{\circ}$ to $90^{\circ}$ at the speed of $10^{\circ}$ per minute. X-ray diffraction pattern provides the information about the crystalline phase as well as the crystallite size. Broadening of the peak indicate the fine size of the nanoparticles, the powder XRD patterns recorded for prepared $\mathrm{CdS}$ nanoparticles calcinated at $60{ }^{\circ} \mathrm{C} 100{ }^{\circ} \mathrm{C}, 140{ }^{\circ} \mathrm{C}$ and $180{ }^{\circ} \mathrm{C}$ for $6 \mathrm{~h}$ are named as CdS- $1, \mathrm{CdS}-2, \mathrm{CdS}-3$ and CdS-4 respectively with the $2 \theta$ values about $26^{\circ}, 44^{\circ}$ and $52^{\circ}$ for cubic system (FCC) with (111), (220) and (311) planes as shown in Figure 1.

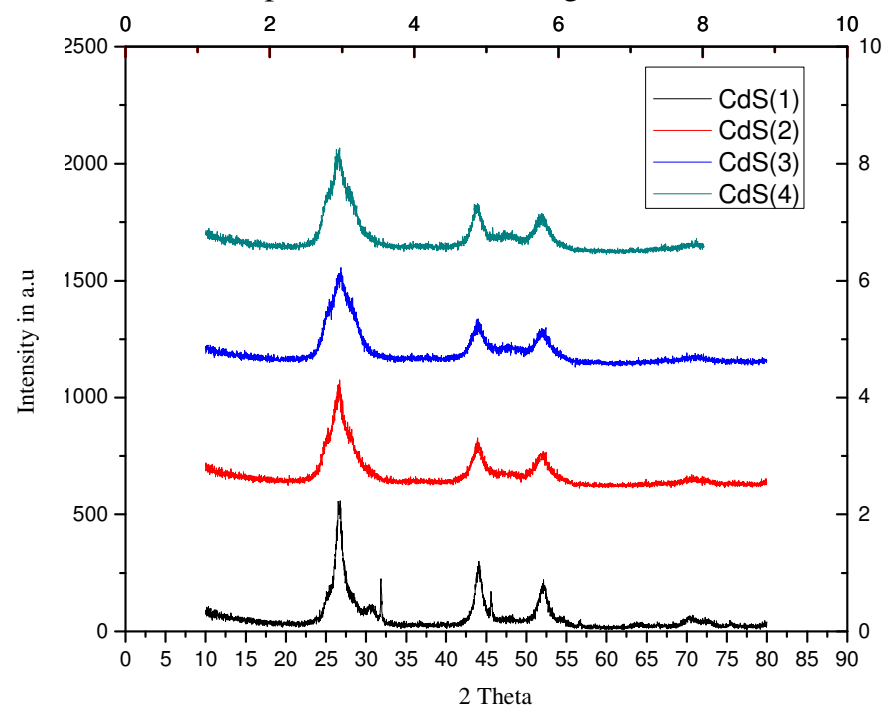

Figure 1. X-ray diffractrograms of CdS nanoparticles

\section{$U V$-Visible spectroscopy}

The most dramatic property of semiconductor is the size evolution of optical absorption spectra. Hence, UV-Visible absorption spectroscopy is an efficient technique to know the optical properties of quantum sized particles. The optical absorption spectra of CdS nanoparticles recorded between 300 to $700 \mathrm{~nm}$ as shown in Figure 2a.

It is observed from the UV-spectra that the shifting of the optical absorption towards lower wavelength (Blue shift) due to the reducing the particle size from CdS-1 to CdS-4 which confirms the results of the XRD. Also it is evident that for CdS nanoparticles, the relation between the mean size and the onset absorption wavelength is related by Henglein's empirical formula.

$$
2 R=\frac{0.1}{0.1338-0.0002345 \lambda e}
$$

Where $\lambda \mathrm{e}$ is the wavelength of absorption onset and $\mathrm{R}$ is the size of the nanoparticles. The calculated size of the CdS nanoparticles by Henglein's formula is also closely agreed with the size of the nanoparticles calculated from XRD pattern using Scherrer's formula. 


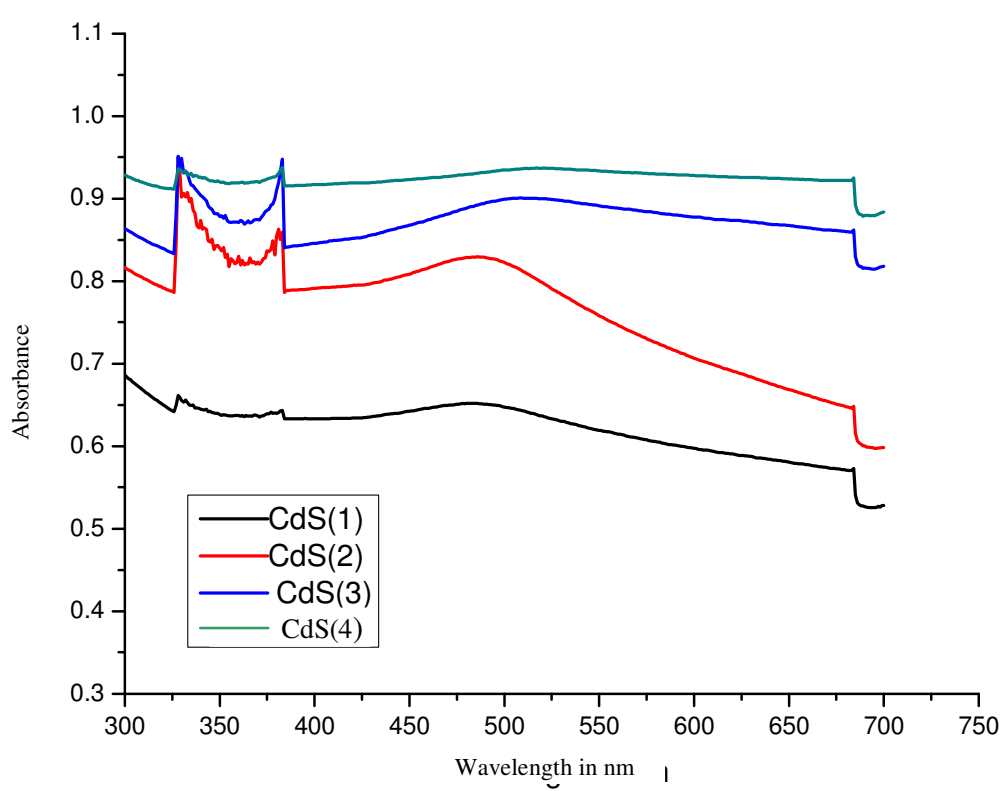

Figure 2a. UV Visible spectra of CdS Nano particles

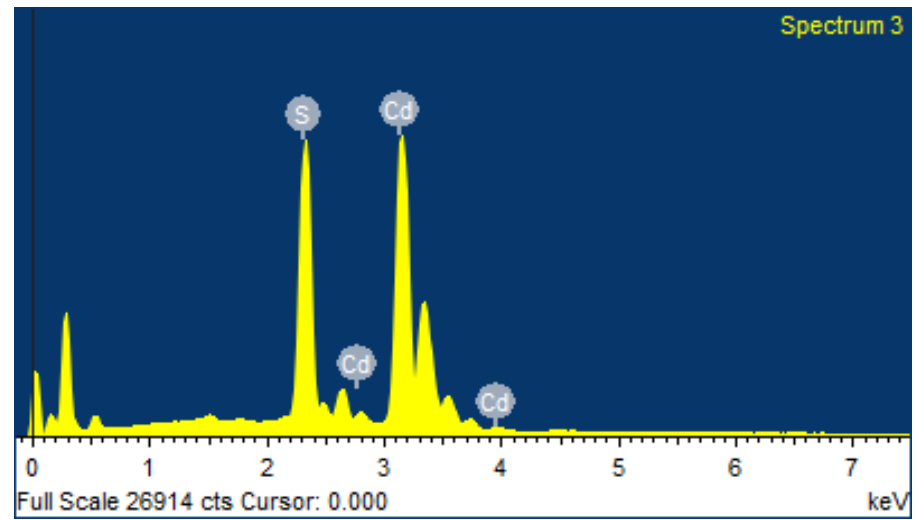

Figure 2b. EDAX of CdS nanoparticles

Scanning electron microscopy

SEM images Figure 3a, 3b \& 3c of CdS nanoparticles revealed that the nanoparticles were agglomerated spherical in shape due to the quantum confinement of the nanoparticles as shown in Figure 3(a-c).

\section{Differential scanning calorimetry}

Analysis of differential scanning calorimetry (DSC) curves shows that the oxidation process for all CdS nanoparticles calcinated at different temperatures shows two weight loss regions. All the endothermic peaks revealed that the initial weight loss in temperature range below $200{ }^{\circ} \mathrm{C}$ mainly corresponds to evaporation of residual solvent (water). The initial weight losses were decreased from CdS-1 to CdS- 4 of DSC curves as shown in Figure 4 with long range due to the increase in calcination temperature as well as reducing the particle size and the secondary weight loss exhibited at almost same temperature. 

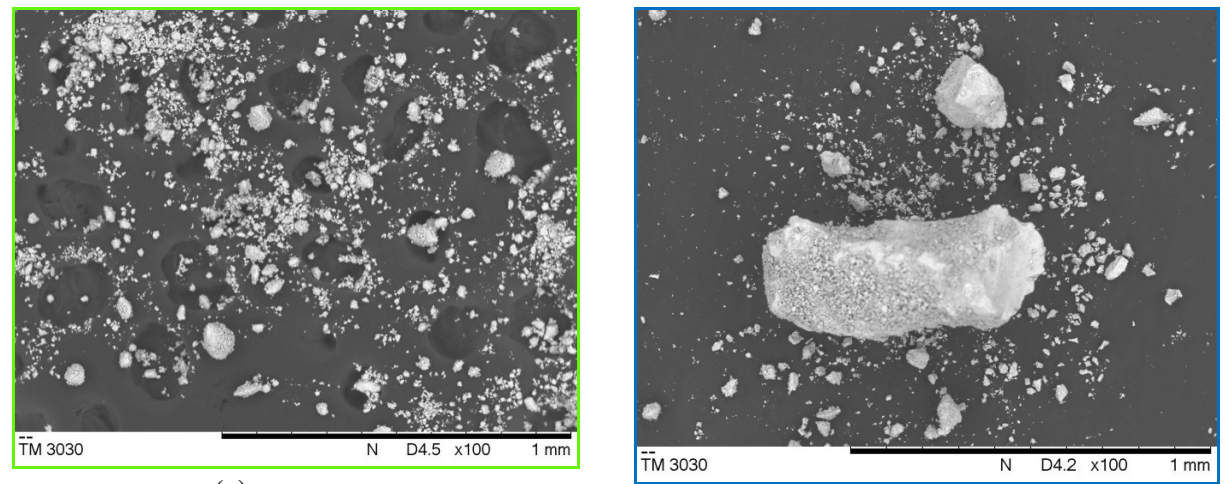

(a)

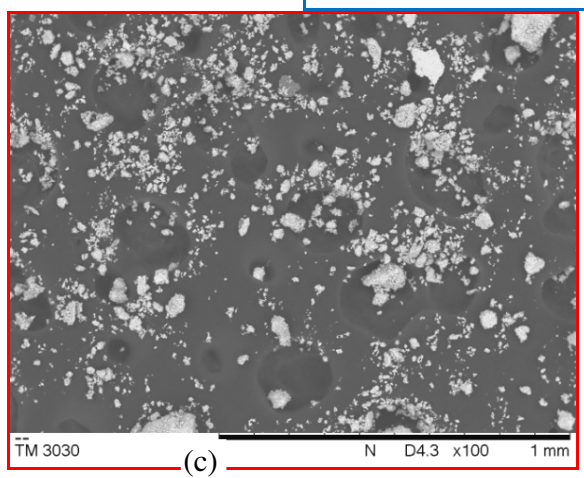

(b)

Figure 3. SEM micrograms of $\mathrm{CdS}$ nanoparticles

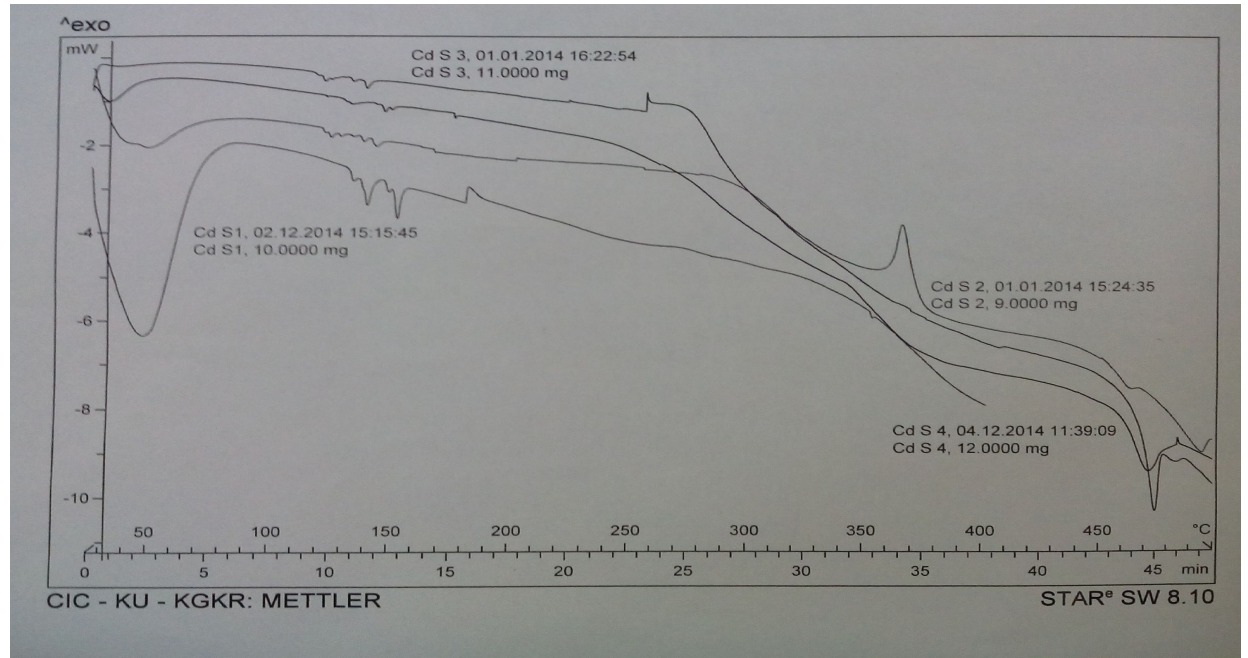

Figure 4. DSC curves of CdS nanoparticles

\section{Conclusion}

In conclusion, we have shown that a variety of nitro compounds were reduced efficiently to their corresponding amines by the $\mathrm{CdS}$ nanoparticles with various sizes under acidic conditions. Herein, we also synthesized and characterized by UV, XRD, SEM and DSC techniques. 


\section{References}

1. Porro S, Musso S, Giorcelli M, Chiodoni A and Tagliaferro A, Physical, 2007, 37, 16-20.

2. Yanbin Cui, Xiaofeng Wu, Hao Wu, Yajun Tian and Chen Yunfa, Mater Lett., 2008, 62(23), 3878-3880; DOI:10.1016/j.matlet.2008.05.011

3. Heron N, Calabrese J C, Farneth W E and Wang Y, Science, 1993, 259, 1426-1428; DOI:10.1126/science.259.5100.1426

4. Hanshaw G, Parkin I P and Shaw G, J Chem Soc., Chem Commun., 1996, 1095-1096; DOI:10.1039/CC9960001095

5. Brus L E, Appl Phys A, 1991, 53(6), 465-474; DOI:10.1007/BF00331535

6. Rossetti R, Hull R, Gibson J M and Brus L E, J Chem Phys., 1985, 82, 552; DOI: $10.1063 / 1.449520$

7. Henglain A, Chem Rev., 1989, 89(8), 1861-1873; DOI:10.1021/cr00098a010

8. Kawar S S, Res J Chem Sci., 2011, 1(8), 31-35.

9. Guptha M, Sharma V, Rev Res J Chem Sci., 2011, 1(2), 135-138.

10. (a) Wang L, Li P, Wu Z, Yan J, Wang M and Ding Y, Synthesis, 2003. 13, 20012004; DOI:10.1055/s-2003-41021 (b) Herepoulos G A, Georgakopoulos S and Steele B R, Tetrahedron Lett., 2005, 46(19), 2469-2473; DOI:10.1016/j.tetlet.2012.03.023 (c) Nagaraja D and Pasha M A, Tetrahedron Lett., 1999, 40(44), 7855-7856; DOI:10.1016/S0040-4039(99)01678-0 (d) Pyo S H and Han B H, Bull Korean Chem Soc., 1995, 16, 181-183.

11. (a) Nomura K, J Mol Catal., 1998, 130(1-2), 1-28; DOI:10.1016/S13811169(97)00141-6 (b) Downing R S, Kunkeler P J and Van Bekkum H, Catal Today, 1997, 37(2), 121-136; DOI:10.1016/S0920-5861(97)00005-9 (c) Boix C and Poliakoff M, J Chem Soc Perkin Trans., 1999, 1, 1487-1490; DOI:10.1039/A901271K

12. (a) Liu Y, Lu Y, Prashad M, Repic O and Blacklock T, J Adv Synth Catal., 2005, 347(2-3), 217-219; DOI:10.1002/adsc.200404236 (b) Hazlet S E and Dornfeld C A, J Am Chem Soc., 1944, 66(10), 1781-1782; DOI:10.1021/ja01238a049

13. Bellamy F D and Ou K, Tetrahedron Lett., 1984, 25(8), 839-842; DOI:10.1016/S0040-4039(01)80041-1

14. Vogel, Practical Organic Chemistry, $5^{\text {th }}$ Ed., 892.

15. (a) Lee D Y and Hartwig J F, Org Lett., 2005, 7(6), 1169-1172; DOI:10.1021/ol050141b (b) Wolter M, Nordmann, Job G E and Buchwald S L, Org Lett., 2002, 4(6), 973-976; DOI:10.1021/o1025548k

16. Pal M, Parasuraman K and Yeleswarapu K R, Org Lett., 2003, 5(3), 349-452; DOI:10.1021/ol027382t

17. Aldrich Catalogue of Fine Chemicals, 2004-2005. 